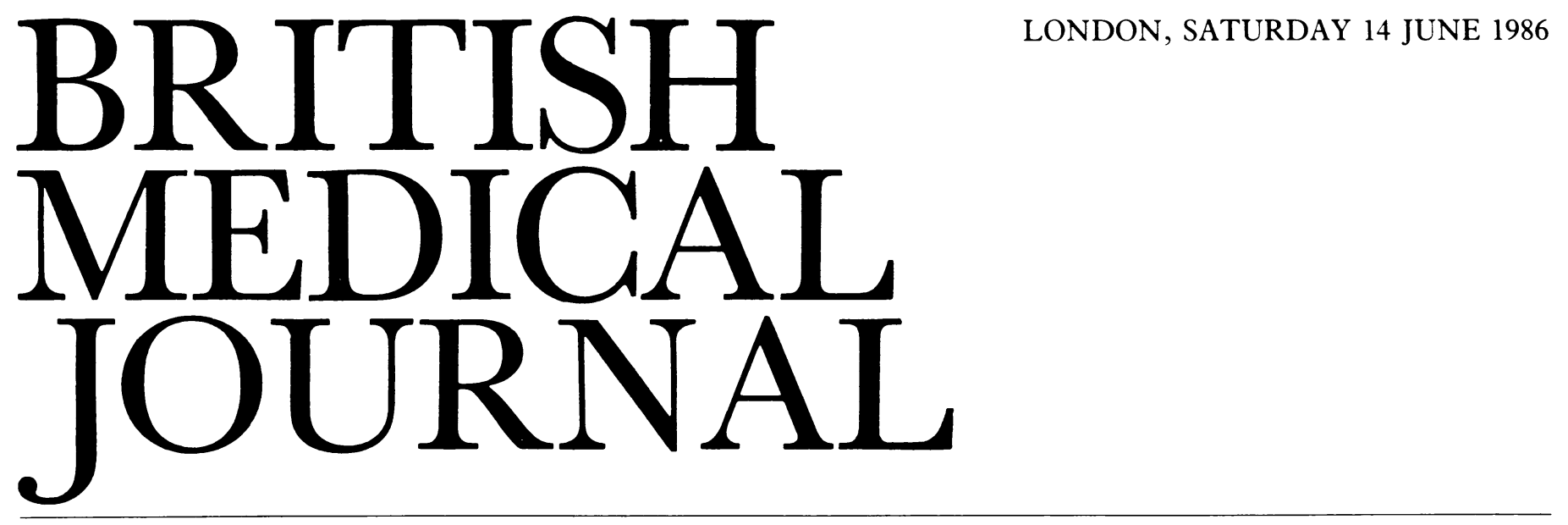

\title{
Reye's syndrome and aspirin
}

Reye's syndrome is now over 20 years old; it was first clearly described by Reye and his colleagues at the Royal Alexandra Hospital for Children, Sydney, Australia, in 1963.' They reported 21 children who developed an acute encephalopathic illness and had dramatic fatty degeneration of the viscera, especially the liver. Seventeen of these children died. Since that time an enormous research effort has been expended in investigating, collecting, and collating data on this syndrome. We now know that it occurs after an infectious illness, typically chickenpox or influenza A or B. ${ }^{2}$ The main features are the encephalopathy, which may cause anything from drowsiness to deep coma, associated with vomiting and enlargement of the liver. There is no jaundice, but the serum transaminase activities and ammonia concentrations are raised, and in severe cases there may be hypoglycaemia and disturbances of the acid-base balance and of blood clotting.

Findings in liver biopsy specimens are characteristic: an unusual pattern of accumulation of fat in the liver cells with fine droplets of lipid occurring throughout the cytoplasm. Electron microscopy shows specific mitochondrial damage.

The full range of Reye's syndrome has only recently been recognised. When Reye first described the condition only the most dramatically affected patients were identified and $80 \%$ of these children died. Mild cases are now known to occur and may be diagnosed at the stage when patients are only in early (grade 1) coma. ${ }^{+}$Indeed, mild Reye's syndrome may be a common cause of vomiting after chickenpox or influenza.

The recorded incidence varies in different parts of the world. A national Reye's syndrome surveillance scheme was set up in Britain in late 1981, and its latest figures showed 82 cases in a 12 month period of 1983-4-an annual incidence of $0 \cdot 7 / 100000$ children under 16.5 The mortality of British patients in $1983-4$ was $41 \%$-rather higher than the $10 \%$ or less reported from many units in the United States, ${ }^{6}$ suggesting that the Americans may be diagnosing more mild cases than we do.

The aetiology of Reye's syndrome is unknown. Careful epidemiological studies over the past few years have linked its occurrence with the administration of salicylates during the antecedent illness. Reports from Ohio, Michigan, ${ }^{\gamma}$ and Arizona ${ }^{4}$ published in the early 1980 s all found this association. Strongly worded reports from the Committee on Infectious Diseases of the American Academy of Pediatrics ${ }^{10}$ and the Surgeon General of the United States Public Health Service ${ }^{11}$ agreed that the administration of aspirin probably contributed to the development of Reye's syndrome and recommended that it should not be given to any children with chickenpox or influenza infections. These early studies have been criticised on epidemiological grounds. ${ }^{12} 13$ A recently published prospective investigation by the United States Public Health Service's task force on Reye's syndrome has carefully considered the alleged methodological errors and has again confirmed the link between the administration of salicylates and Reye's syndrome. ${ }^{1+}$ There can now be no reasonable doubt that aspirin given to a child infected with chickenpox or influenza increases his or her risk of developing Reye's syndrome.

How important is this increased risk? We should be more careful about our general paediatric prescriptions for aspirin than we have been in the past. That means we should ensure that there is a genuine reason for its use. In addition, we should use a non-salicylate alternative such as paracetamol as a first line antipyretic. The Committee on Safety of Medicines has just written to doctors giving advice in line with these recommendations ( $p$ 1590).

What about children having long term salicylates for juvenile chronic arthritis "rheumatoid arthritis" of childhood)? Salicylates are a mainstay of their treatment and are by far the most widely used of all the non-steroidal antiinflammatory drugs in this condition. There is no evidence that any other drug would be safer, and it would be premature to panic about their continued use. Perhaps a reasonable compromise at present in these children would be to substitute an alternative non-steroidal anti-inflammatory drug for aspirin in the event of a known local epidemic of chickenpox or influenza. To my knowledge no case of Reye's syndrome has yet been reported in Britain in a child having long term salicylates. Let us keep the problem in perspective and refine our guidelines further only when we have a clearer understanding of the relation between Reye's syndrome and salicylates.

Michael TARLOW

Senior Lecturer in Paediatrics,

University Department of Paediatrics and Child Health,

East Birmingham Hospital Teaching Unit,

Birmingham B9 5ST 1 Reve RDK, Morgan G, Baral J. Encephalopathy and fatty degeneration of the viscera. A disease
entity in childhood. Lancet $1963 ;$ ii: $749-52$.
2 Sullivan-Bolvai JZ. Corey L. Epidemiology of Reye syndrome. Epidemol Rev 1981;3:1-26.
3 Partin JC, Schubert W'K, Partin JS. Mitochondrial ultrastructure in Reye's syndrome encephalo-
pathy and fatty degeneration of the viscera . N Engl $\mathcal{F}$. Med 1971;285:1339-43.
4 Lichtenstein PK, Heubi JE, Daugherty CC, et al. Grade I Reye's syndrome: a frequent cause of
vomiting and liver dysfunction after varicella and upper respiratory tract infection. N Engl $\mathcal{F}$ lied 1983;309:133-9. 
5 Anonymous. Reve's syndrome surveillance scheme: third annual summary report. Br. Hed 7 $985: 291: 329-30$

6 De Vivo DC. How common is Reve's syndrome? N Engl f. Hed 1983:309:179-81.

Haipin TJ. Holtzhauser FJ. Campbell RJ, et al. Reve's sundrome and medication use, 7.1.11. 1982:248:68:-91.

\& Waldman RJ. Hall W.X. MeGee H. el al. Aspirin as a risk factor in Reve's sundrome. F.1.11.t 1982:247:3089-94.

tarko K.II. Ray CG. Dominquer LB, et al. Reve's indrome and salicilate use. Pediatris 1980:66:859-6t.

1i) Committee on Intectious Disease Aspirin and Reve syndrome Pedium 1982:69:810-2.

11 Anonimous. Surgeon General's advisory on the use of salicilates and Reve undrome. HH.HWW $R$ $19 \times 2 \cdot 31 \cdot 289-90$

12. Willon JT. Brown RI). Reve sundrome and aspirin use: the role of prodromal illness seserity in the assessment of relative risk. Pediatmis 1982:69:8:2.5.

13 Heckelman R.A. Take two aspirin and call me in the morning. A 7 f Dis (hild 1982:136:973-4.

14 Hurwit/ ES. Barrett .11J. Bregman D. et al. Puhlic Health Service tudy on Reve's stindrome and medications. Report of the pilot phase. N Lin! 7 .11ed 1455:313:849-5-

\section{Airing operating theatres}

The prime importance of airborne infections is one of the oldest medical beliefs; it is evidenced by terms such as the Anglo-Saxon "elf shot," the still current "malaria," and the all pervasive "miasma," which was banished less than a century ago. These concepts were erroneously used to describe the modes of spread of insect borne pestilences and gastrointestinal infections notably typhoid and cholera. The doctrine of miasmatic effluvia is not, however, totally lost: its last strongholds include-with some justification-operating theatres.

The first rational attempt to disinfect the air around the operation site was abandoned in 1887 , when after 16 years' use Lister realised that his carbolic acid spray was the least important and most unpleasant part of his antiseptic system. $\mathrm{He}$ and his followers then concentrated their efforts on the main sources of "septic defilement"-the hands of the operators, the skin incision, and the surgical materials and instruments. The development of asepsis on a foundation of antisepsis provided substantial protection against postoperative wound infections. Today this protection continues to depend largely on a battery of procedures and rituals which have remained essentially unchanged for the past 80 yearsdespite close scrutiny recently. ${ }^{1}$

Interest in airborne infection is, however, now increasing again. This is partly because of the control of other exogenous sources but also because a very low dose of bacterial inoculum is believed to be capable of initiating infection in some current procedures, notably the insertion of prosthetic implants. For example, in hip joint replacement the deposition in the open wound of as few as 10 airborne particles carrying skin commensal bacteria of low pathogenicity is said to be associated with a rate of joint sepsis of $1 \%$ rising to over $5 \%$ when the dose exceeds 100 particles. ${ }^{3}$

This boldly quantitative conclusion was the outcome of a randomised prospective study in 19 hospitals comparing the effects of conventional ventilation and "ultraclean" air on rates of joint sepsis after total replacement of the hip or knee joint. The clinical results were impressively clear: operations in ultraclean air with staff wearing conventional theatre clothing were associated with roughly one half the sepsis rate of those performed in theatres with standard "plenum" ventilation, when $2-5 \%$ of patients developed joint infection. ${ }^{4}$ If body exhaust suits were worn to supplement the ultraclean laminar air ventilation the sepsis rates fell by a further half to less than $1 \%$. The bacterial air counts observed in the three sorts of environment ranged from 50 to over 500 "colony forming units" or particles per cubic metre in conventional ventilation, two to 20 in ultraclean air, and one or fewer when the special suits were worn. ${ }^{3}$ An apparently irreducible joint sepsis rate of around $0.5 \%$ is presumably due to the patient's own residual skin bacteria at the operation site.

The heterogeneous array of ventilation systems used in British operating theatres provides a living historical record of the subject. Some older hospitals still rely on unmodified natural ventilation, particularly in outpatient theatres used for minor urological or gynaecological procedures. Yet even caesarean sections - entailing considerable tissue exposureare sometimes performed in such conditions. Airborne particles carrying bacteria from outside the suite readily flow into the theatre on thermal currents; indeed, this bacterial contamination may be increased by the use of extractor fans to remove heat and steam. Comfort is achieved by actively drawing in vitiated air from the adjacent hospital corridor.

The controlled access of bacteria to the operation site was greatly ameliorated after the introduction of ventilation systems based on the 1962 specifications of the Medical Research Council. 5 A small excess in the volume of airfiltered down to $5 \mathrm{um}$ particle size-is pumped into the operating room to prevent the entry of suspended bacteria into the theatre suite from other parts of the hospital. The combination of this plenum air flow of between 20 and 40 changes an hour, the controlled architectural plan, and staff circulation will maintain a gradient of bacterial air counts from the lowest at the centre of the operating room to the highest in the least critical areas, including the exit into the outer access corridor. ${ }^{6}$ Despite the incorporation of humidification systems there has fortunately been no report of legionella infection acquired in the theatre. Awareness of this hazard must, however, be maintained.

An inherent defect of the plenum system is the unavoidable air turbulence generated in the area of the operation. This is due to a combination of the diffuse entry of clean air from the air conditioning system, the movements of theatre staff, and convection driven by the hot operating lamps. This turbulence distributes bacterial contaminants, most of which are carried on microscopic skin scales derived mainly from the staff, and readily reaching the air through conventional operating gowns and trousers. This is an important infection hazard only in specialised procedures such as implant surgery-where laminar ventilation systems provide valuable protection. The Charnley-Howorth "exponential" downflow enclosure has been particularly satisfactory in this respect. ${ }^{3}$ It functions economically at 40 air changes an hour, with filtration down to $1 \mu \mathrm{m}$ particle size.

Additional economies may possibly be achieved without jeopardising safety by simply switching off the main theatre ventilation during quiet periods. This was the conclusion from a recent detailed air study on plenum systems: all was well provided they were switched on again one hour before preparing for surgery and the areas surrounding the theatre were continuously maintained at positive pressure to prevent entry of airborne contamination from the rest of the hospital. ${ }^{9}$ If these findings can be shown to apply under the very rigorous conditions of laminar downflow systems the cost savings should encourage the installation of many more. This form of ventilation is a prime example of the high technology which should be available in any hospital undertaking the more demanding procedures of modern surgery.

SYDNEY SELWYN

Professor of Medical Microbiology

Charing Cross and Westminster Medical School, London SW 1P 2AR 